
\title{
R Research Soure \\ Internet-based Cognitive-behavioral Therapy for Premenstrual Syndrome: A Randomized Controlled Trial
}

\section{Sanam Borji-Navan}

Tabriz University of Medical Sciences

Sakineh Mohammad-Alizadeh-Charandabi ( $D$ mhammadalizadehs@gmail.com )

Tabriz University of Medical Sciences https://orcid.org/0000-0003-4785-9333

Khalil Esmaeilpour

University of Tabriz

Mojgan Mirghafourvand

Tabriz University of Medical Sciences

Ali Ahmadian-Khooinarood

Tabriz University of Medical Sciences

Research article

Keywords: Cognitive behavior therapy, ICBT, Internet-based treatment, Premenstrual syndrome, Quality of life

Posted Date: May 19th, 2021

DOI: https://doi.org/10.21203/rs.3.rs-328691/v2

License: (c) (1) This work is licensed under a Creative Commons Attribution 4.0 International License.

Read Full License

Version of Record: A version of this preprint was published at BMC Women's Health on January 8th, 2022. See the published version at https://doi.org/10.1186/s12905-021-01589-7. 


\section{Abstract}

Background: Premenstrual Syndrome (PMS) is a common problem among women of reproductive age, affecting various aspects of their lives. There are very limited studies investigating the effect of InternetBased Cognitive-Behavioral Therapy (ICBT) on PMS. We aimed to investigate the effect of ICBT on symptom severity of women suffering from PMS and their quality of life in the perimenstrual and late follicular periods.

Methods: Ninety-two university students aged 18-35 years with moderate to severe PMS were allocated into two groups of 46 using block randomization. The intervention group underwent ICBT for two menstrual cycles, while the control group received no intervention. All participants filled the Daily Record of Severity of Problems (DRSP) for two menstrual cycles and the Quality of Life Enjoyment and Satisfaction Questionnaire - Short Form (Q-LES-Q-SF) on days 1-2 and 11-13 of the menstrual cycle preand post-intervention. Data were analyzed using univariate general linear models.

Results: Four students in the intervention group were lost to follow-up. Post-interventionally, the mean score of total PMS symptoms was significantly lower in the intervention group than the control group (10.4 vs. 20.2 , adjusted difference: -9.9 [95\% $\mathrm{Cl}:-13.3$ to -6.6$]$ ) and perimenstrual quality of life was significantly higher (64.2 vs. 50.3, 14.1 [8.5 to 19.8]). However, there was no significant intergroup difference in the late follicular quality of life (68.3 vs. $67.3,1.9$ [-4.4 to 8.1]).

Conclusions: Internet-Based Cognitive-Behavioral Therapy could effectively reduce PMS symptom severity and improve perimenstrual quality of life, with no significant effect on the late follicular quality of life.

Trial registration: The Iranian Registry of Clinical Trials, Identifier: IRCT20100414003706N34, Registered 19 June 2019, https://www.irct.ir/trial/38394

\section{Background}

Some women experience several troublesome symptoms during the premenstrual period, a condition known as Premenstrual Syndrome (PMS) [1]. According to the Diagnostic and Statistical Manual of Mental Disorders, 5th edition (DSM-5), the diagnosis can be made if the individual experiences at least five symptoms, including at least one affective symptom, of PMS symptoms within one week before menstruation for two consecutive cycles [2]. The symptoms should be severe enough to interfere with the patient's daily life [3].

Overall, PMS affects about $20 \%$ of women of childbearing age $[4,5]$. The condition leads to various consequences, including physical (cardio-pulmonary, genitourinary, neurological, gastrointestinal, and musculoskeletal disorders), psychological (mood, cognitive, and emotional disorders), behavioral (changes in sleep and eating patterns), and social (defective interpersonal relationships, sexual dysfunction, and social isolation) complications [6]. Symptoms can significantly impact the quality of life 
[7], especially during the premenstrual period [8]. Given the high importance of assessing the quality of life of patients with chronic problems [9], it is, therefore, necessary to investigate the potential effect of various interventions on the quality of life of women suffering from PMS.

Our understanding of the cause and pathophysiology of PMS is not complete. A great deal of PMS is still unknown to us [10]. It is one of the most troublesome and common complaints of women at medical visits for which there is no definitive cure. Therefore, there is an essential need for effective and acceptable methods with no or low side effects to relieve PMS symptoms [11].

Some studies have shown the effectiveness of cognitive-behavioral therapy on PMS symptoms [12-14]. However, the method is not feasible for some women due to factors such as distance and time constraints and the relatively high cost of therapy [15]. We found only one study that investigated the effect of Internet-Based Cognitive-Behavioral Therapy (ICBT) on PMS. The study was conducted in Germany and had promising results [16]. Given the influence of social, cultural, and psychological factors on PMS [17], the results of ICBT interventions in one region cannot be generalized to other areas with different social and cultural backgrounds. Therefore, the present study aimed to investigate the effect of ICBT on symptom severity and quality of life of women suffering from PMS, as primary outcomes, as well as PMS-related disability and attitude toward menstruation, as secondary outcomes.

\section{Methods}

\section{Study design and participants}

This randomized controlled trial was approved by the Ethics Committee of Tabriz University of Medical Sciences with the approval code of IR.TBZMED.REC.1398.014 and was registered at the Iranian Registry of Clinical Trials with the registration code of IRCT20100414003706N34. Participant recruitment was then conducted. We followed the CONSORT guidelines.

The inclusion criteria were healthy university students aged 18-35 years who lived in the residence halls of the Tabriz University of Medical Sciences (4 residence halls with approximately 1200 students), had a regular menstrual cycle duration of 25-35 days in the past 6 months, had moderate to severe PMS symptoms diagnosed using prospective Daily Record of Severity of Problem (DRSP) for 2 menstrual cycles, and did not currently use treatment for PMS or Premenstrual Dysphoric Disorder (PMDD).

Exclusion criteria included professional athletes; pregnant and postpartum women (within 1 year of delivery); women who were breastfeeding their babies; individuals with current major depression; students with a history of a major psychiatric disorder, including psychosis, bipolar disorder, eating disorder, and severe depression; persons with a history of drug, alcohol, or hookah use within the past two years; patients who had taken antidepressants, benzodiazepines, anticancer drugs, oral contraceptives, or hormones in the past three months; individuals who were affected by diseases such as gastrointestinal, cardiovascular, renal, and endocrine disorders or epilepsy; students who had experienced a highly stressful event such as parental divorce or death of a first-degree family member in the past six months; 
those with gynecological problems such as previous hysterectomy, oophorectomy, gynecological cancer, polycystic ovary syndrome, endometriosis, and infertility; students with no access to Internet; or those who did not have an e-mail account or phone number.

All exclusion criteria were applied based on the personal reports of the participants, except for major depression, which was assessed using the Beck questionnaire and the DRSP. We also attempted to include students living in two private residence halls (approximately 225 students). However, there was no cooperation from those in charge. Therefore, we excluded these students.

\section{Sample size}

We considered a sample size of 92 ( $n=46$ for each group) based on PMS scores from a previous study conducted in a similar study setting ( $M 1=163.6, \mathrm{SD} 1=89.5)$ [18], with an estimated $35 \%$ reduction in mean PMS score by the intervention ( $M 2=106.3$, SD2 $=$ SD1), two-sided $a=0.05$, power $=80 \%$, and $15 \%$ probability of loss to follow-up. This sample size was sufficient to meet other study objectives with a power greater than $80 \%$.

\section{Recruitment \& Randomization}

First, potential participants selected using a checklist of initial eligibility criteria completed the sociodemographic and reproductive questionnaire and a validated Persian version of the 19-item Premenstrual Symptoms Screening Tool (PSST) [19]. According to the PSST developers [20], PMS screening is positive when the woman reports at least five of 14 PMS symptoms. The reported symptoms must be moderate or severe, and at least one of them must be one of the four main PMS symptoms. In addition, the symptoms must moderately to severely interfere with at least one of the five domains of life.

Participants gave written informed consent. Then, those with positive PMS screening were asked to complete the DRSP during a menstrual cycle. In addition, they were asked to complete the validated Persian version of the 21-item Beck Depression Inventory [21] on one of the days after the menstruation end and before the first day of the estimated luteal phase. The participants with a score of 29 or higher on the Beck questionnaire [22] were diagnosed with major depression and subsequently excluded from the study. The remaining participants were asked to complete the DRSP during a second menstrual cycle, as well as the Sheehan Disability Scale (SDS) and the Menstrual Attitude Questionnaire (MAQ) on day 12 of menstruation and the Quality of Life Enjoyment and Satisfaction Questionnaire - Short Form (Q-LESQ-SF) on days 1-2 and 11-13 of the menstrual cycle. Participants with symptoms of major depression in the follicular phase based on the 2-cycle DRSP were also excluded.

The female students with moderate to severe PMS, diagnosed based on the DRSP, were finally included in the study. They were randomly allocated into the intervention and control groups using the block randomization method. Allocation sequence was generated with randomly varied block sizes of four and 
six and an allocation ratio of 1:1 using an online program (www.random.org). The sequence generation was performed by an individual who was not involved in participant recruitment and data collection. In addition, the central telephone method was used for allocation concealment, while participant recruitment was done by the first author (SB).

Only one eligible participant was recruited from each room in the residence hall (each room usually had 3-6 students) to prevent contamination. Approximately $20 \%$ of participants were not present in the residence hall during most of the intervention period because it was semester break or the university was closed due to the COVID - 19 pandemic.

\section{Intervention}

The research team developed educational content for 8 sessions (one session per week) by reviewing all the literature and using the intervention content of the previous study in this field [16] and the comments of some experts in reproductive health and psychology. The sessions' contents were mainly focused on the intervention content of the previous study in Germany [16]. For example, the general information on PMS/PMDD and the etiology were presented in the first session, while the last session included the instructions for the patients, such as the methods for relapse prevention. Both the cognitive and behavioral strategies were discussed in sessions $2,3,4,5,6$, and 7 . The cognitive strategies discussed in the sessions were as follows:

- Session 2: Psychological training on the role of thoughts and their relationship with emotions and behavior (cognitive triangle)

- Session 3: Changing to the certain topic of PMS

- Session 4: Reconstruction of dysfunctional perceptions

- Session 5: Psychological training on specific superstitions about PMS and application of the cognitive strategies learned

- Session 6: Psychological training on effective thoughts and developing new assessments

- Session 7: Certain behaviors to improve PMS (use of healthcare, seeking support, and communication)

Moreover, the behavioral strategies discussed in the sessions were the following subjects:

- Session 2: Psychological training on the relationship between stress and PMS and teaching relaxation techniques

- Session 3: Psychological training on the interdependence between nutrition, exercise, and PMS

- Session 4: How to integrate exercise into daily life using a motivational program and strategy

- Session 5: What is a balanced diet and how to follow it in the daily life

- Session 6: Psychological training on the impact of stress-related errors on reasoning 
- Session 7: Training on participating in positive activities in daily life

The participants were provided with audiovisual material to facilitate learning practical exercises such as relaxation techniques, exercises related to thought change, and physical exercises, including yoga.

When the educational content was prepared, the principal investigator (SB) designed a counseling course in the Learning Management System (LMS) website of the Tabriz University of Medical Sciences (Modular Object-Oriented Dynamic Learning Environment (MOODLE), https://moodle.org). The course was designed under the supervision of the person in charge (AA) of the university LMS website.

Special accounts were created for each member of the intervention group, and the account information was sent to them via E-mail, SMS, and one of the social media platforms they used. The intervention group received the contents in a scheduled manner. When a piece of content was loaded on the website, the participants received an e-mail or SMS. In addition, we created a telegram channel for them, through which we sent them daily reminders to visit the website and receive the educational content. In addition, participants were instructed how to use the LMS website before the course, and those who did not log in to their account within the first week of the course were reminded by telephone. Also, they could ask questions online and receive answers from the principal investigator (SB).

In order to check the treatment adherence, the participants were assigned homework at the end of each session and were supposed to submit their weekly feedback using the website or social media platforms. The participants with delays in sending feedback were reminded via SMS. In case of no answer, we called them by phone. Also, they received calls from the principal investigator every two weeks to keep them motivated. In these calls, the principal investigator discussed the strategies with the participants, asked about the effectiveness of the strategies for them, received the suggestions and criticisms, asked them to write their questions using the LMS website, and answered the questions.

The control group did not receive any intervention during the study period. When all post-test assessments were done, the accounts of the control group were created, and they received the intervention.

\section{Data collection tools}

We used the following tools to evaluate the severity of PMS symptoms and quality of life of the participants (primary outcomes), as well as the PMS-related disability and attitude toward menstruation (secondary outcomes):

\section{Researcher-made demographic and gynecologic questionnaire}


The questionnaire was prepared by reviewing the literature in this field and included three parts: demographics, contact information, and gynecologic information, including menstrual history. The face and content validity of the questionnaire was determined by 10 experts in this field.

\section{Daily Record of Severity of Problems (DRSP)}

This scale is a valid scale widely used for PMS diagnosis and is consisted of 21 items on 11 domains of PMS symptoms, including depression, anxiety, mood lability, anger, interest, concentration, lethargy, appetite, sleep, overwhelm, physical symptoms, and 3 impairment items. Each item is scored on a scale of 1 (not at all) to 6 (extreme) [23]. The questionnaire must be completed for at least two consecutive cycles. A PMS diagnosis is made if a person has a score of 4 (moderate) or higher in 5 or more of the symptoms for at least 2 days in the late luteal phase (days -5 to -1 of the menstrual cycle). The score of 4 or higher should be in at least one of the items assessing depression, anxiety, affective lability, or anger/irritability, and in at least one of the 3 impairment items. However, she must not have a mean score higher than 3 (mild) in any of the symptoms during the mid-follicular phase (days +6 to +10 of the menstrual cycle) [24].

In a study by Ozgoli et al., the internal consistency of the Persian version of this scale was good (Cronbach's alpha $=0.80)$ [25]. In the present study, the reliability of the scale was also confirmed, with a Cronbach's alpha equal to 0.97 for the total scale and $0.82-0.91$ for the domains. In addition, the testretest agreement was good for the total DRSP [intraclass correlation coefficient (ICC) $=0.815,95 \% \mathrm{Cl}$ : 0.720 to 0.878$]$.

\section{Quality of Life Enjoyment and Satisfaction Questionnaire - short form (Q-LES-Q-SF)}

This unidimensional tool includes 14 items scored on a five-point Likert scale (very poor, poor, fair, good, and very good) and assesses the quality of life during the last week. Higher scores indicate higher quality of life. The reliability of the Persian version of this questionnaire has been confirmed on the university students in Kashan (ICC = 0.97-0.98, Cronbach's alpha $=0.93$ ) [26] and Tabriz (Cronbach's alpha = 0.8870.937) [8].

The women suffering from PMS have different levels of quality of life in perimenstrual compared to late follicular period [8]. Therefore, the participants filled the questionnaire twice, once at days 1-2 and once at days 11-13 of the menstrual cycle. The internal consistency of the scale was good for both assessments (Cronbach's alpha $=0.86$ and 0.85 , respectively). The test-retest agreement (between the two pre-intervention assessments) was good as well (ICC $=0.783,95 \% \mathrm{Cl} ; 0.672$ to 0.856 ).

\section{Sheehan Disability Scale (SDS)}


This questionnaire is a self-report scale on disability and dysfunction [27] that evaluated the disturbances in 3 areas of work/school, social life, and family life/home responsibilities using a 0-10 visual analogue scale [28]. In the present study, we combined the scores of these 3 areas to obtain a total SDS score [29]. The Persian version of the scale has good internal consistency (Cronbach's alpha $=0.88$ ) [28]. Its reliability in the present study was confirmed as well (Cronbach's alpha $=0.67$ ).

\section{Menstrual Attitude Questionnaire (MAQ)}

This questionnaire includes 33 items in 5 domains, with 5-7 items in each domain. The items are scored on a 7-point Likert scale (from "strongly disagree" to "strongly agree"), with some items with negative concepts being reversely scored [30]. In the present study, the internal consistency was confirmed for all domains (Cronbach's alpha $=0.66-0.83$, menstruation as a debilitating event $=0.82$, menstruation as a bothersome event $=0.79$, menstruation as a natural event $=0.83$, anticipation and prediction of the onset of menstruation $=0.66$, denial of any effect of menstruation $=0.66$ )

\section{Participant satisfaction and views on intervention effectiveness}

The satisfaction of participants with the intervention was assessed using a question scored on a 5-point Likert scale (from "very satisfied" to "very dissatisfied"), while their opinions on the effectiveness of intervention were assessed using another question scored on a 6-point Likert scale (from "not at all" to "very high").

Pre-intervention assessments are already described in the sub-section of "participant recruitment." Following the two month intervention duration, all participants started to complete the DRSP for the next two cycles. Also, they completed the Q-LES-Q-SF, SDS, and MAQ in month 3 after the allocation, at the same times of the menstrual cycle the pre-test questionnaires were filled. At the end of the intervention period, the intervention group reported their satisfaction levels with the intervention and their opinions on its effectiveness. Most questionnaires were filled online by the participants for higher accessibility.

\section{Data analysis}

Data analysis was performed using the SPSS version 25. The normality of the quantitative variables' distribution was confirmed using the one-sample Kolmogorov-Smirnov test by group. In order to evaluate the effect of the intervention, univariate general linear models were used for intergroup comparisons of the post-intervention assessment values, which were adjusted for the baseline values. $a=0.017$ was considered the significance level for the three primary outcomes because the multiple comparisons were corrected using the Bonferroni correction method, while $a=0.05$ was considered the significance level for other comparisons. We used the modified intention-to-treat (ITT) analysis while excluding the four participants lost to follow-up. 


\section{Results}

679 students were screened based on the eligibility criteria from Jun 2019 to January 2020. Finally, 92 students were considered eligible and agreed to participate in the study (46 were allocated in each group). Four students in the intervention group were lost to follow-up and were excluded from the analysis (Fig. 1). Data collection was completed in June 2020.

PMS: premenstrual syndrome, PSST: Premenstrual Symptoms Screening Tool, DRSP: Daily Record of Severity of Problems, SDS: Sheehan Disability Scale, MAQ: Menstrual Attitude Questionnaire, QLES-Q-SF: Quality of Life Enjoyment and Satisfaction Questionnaire Form

The two groups were similar in the following variables: demographic and gynecologic characteristics (Table 1), pre-test scores of symptom severity (except physical symptoms), quality of life, and attitude towards menstruation (Table 2). The mean (SD) age and BMI of the participants were 22.1 (2.7) years and $21.9(2.5) \mathrm{kg} / \mathrm{m}^{2}$, respectively. $9.8 \%$ of the participants were married. The mean score of baseline total PMS symptoms was 20.3 (SD 10.5). 
Table 1

Baseline characteristics of participants by the study groups

\begin{tabular}{|lll|}
\hline Variable & Intervention $(\mathbf{n = 4 6 )}$ & Control $(\mathbf{n}=\mathbf{4 6})$ \\
\hline Age (years) & $22.1(2.7)$ & $22.3(2.5)$ \\
\hline Menarche age (years) & $12.9(1.2)$ & $13.0(1.3)$ \\
\hline PMS Score (assessed by PSST) & $32.6(6.8)$ & $31.5(6.4)$ \\
\hline Depression score (assessed by Beck) & $9.4(6.9)$ & $8.9(7.2)$ \\
\hline Body mass index (kg/m $\left.{ }^{2}\right)$ & $22.1(2.5)$ & $21.6(2.5)$ \\
\hline Marital status (Married) & $5(11 \%)$ & $16(35 \%)$ \\
\hline Educational grade (Master and above) & $14(309 \%)$ & $29(63 \%)$ \\
\hline Family history of PMS (yes) & $34(74 \%)$ & $10(22 \%)$ \\
\hline Regular exercise (yes) & $10(22 \%)$ & $23(46 \%)$ \\
\hline Sufficiency of family income & $15(33 \%)$ & $2(4 \%)$ \\
\hline Totally & $28(61 \%)$ & \\
\hline To some extent & $3(6 \%)$ & \\
\hline Not at all & & \\
\hline $\begin{array}{l}\text { Intervention group received web-based counselling with cognitive-behavioural approach for eight } \\
\text { weeks and control group received no intervention } \\
\text { PMS: premenstrual syndrome, PSST: Premenstrual Symptoms Screening Tool }\end{array}$ & \\
\hline $\begin{array}{l}\text { Data present mean (SD) or number (percent) } \\
\text { * T-test for comparison of the means and Chi-square for comparison of the frequencies }\end{array}$ \\
\hline
\end{tabular}


Table 2

Outcomes by study groups

\begin{tabular}{|c|c|c|c|c|c|c|}
\hline \multirow[t]{2}{*}{ Outcomes } & \multicolumn{2}{|l|}{ Baseline } & \multicolumn{4}{|c|}{ Post-intervention } \\
\hline & $\begin{array}{l}\text { Intervention } \\
\mathrm{n}=46\end{array}$ & $\begin{array}{l}\text { Control } \\
n=46\end{array}$ & $\begin{array}{l}\text { Intervention } \\
n=42\end{array}$ & $\begin{array}{l}\text { Control } \\
n=46\end{array}$ & $\begin{array}{l}\text { adjusted } \\
\text { difference } \\
(95 \% \mathrm{Cl})\end{array}$ & $\begin{array}{l}\mathrm{p}- \\
\text { value }\end{array}$ \\
\hline \multicolumn{7}{|l|}{ Primary outcomes } \\
\hline $\begin{array}{l}\text { Total score of } \\
\text { premenstrual syndrome } \\
\text { severity }^{\dagger}(0-100)\end{array}$ & $20.1(10.7)$ & $\begin{array}{l}20.4 \\
(10.3)\end{array}$ & $10.4(10.0)$ & $\begin{array}{l}20.2 \\
(10.0)\end{array}$ & $\begin{array}{l}-9.9(-13.3 \\
\text { to }-6.6)\end{array}$ & $<0.001$ \\
\hline \multicolumn{7}{|c|}{ Quality of life and satisfaction $(0-100)^{\ddagger}$} \\
\hline Peri-menstrual period & $49.3(16.4)$ & $\begin{array}{l}50.4 \\
(12.8)\end{array}$ & $64.2(15.4)$ & $\begin{array}{l}50.3 \\
(10.8)\end{array}$ & $\begin{array}{l}14.1(8.5 \\
\text { to } 19.8)\end{array}$ & $\begin{array}{l}< \\
0.001\end{array}$ \\
\hline Late follicular period & $63.0(14.1)$ & $\begin{array}{l}65.5 \\
(10.3)\end{array}$ & $68.3(15.4)$ & $\begin{array}{l}67.3 \\
(12.3)\end{array}$ & $\begin{array}{l}1.9(-4.4 \\
\text { to } 8.1)\end{array}$ & 0.975 \\
\hline \multicolumn{7}{|l|}{ Secondary outcomes } \\
\hline \multicolumn{7}{|c|}{ Sub-scales of premenstrual syndrome symptoms } \\
\hline $\begin{array}{l}\text { Depressive symptoms (0- } \\
\text { 100) }\end{array}$ & $19.1(12.5)$ & $\begin{array}{l}18.8 \\
(11.6)\end{array}$ & $8.7(10.2)$ & $\begin{array}{l}18.6 \\
(10.5)\end{array}$ & $\begin{array}{l}-10.2 \\
(-13.0 \text { to } \\
-7.3)\end{array}$ & $\begin{array}{l}< \\
0.001\end{array}$ \\
\hline $\begin{array}{l}\text { Physical symptoms (0- } \\
100)\end{array}$ & $15.1(9.4)$ & $\begin{array}{l}20.2 \\
(12.9)\end{array}$ & $12.7(9.0)$ & $\begin{array}{l}18.6 \\
(12.4)\end{array}$ & $\begin{array}{l}-2.1(-4.1 \\
\text { to }-0.1)\end{array}$ & 0.041 \\
\hline Anger/Irritability (0-100) & $26.3(15.6)$ & $\begin{array}{l}24.2 \\
(15.9)\end{array}$ & $12.9(13.1)$ & $\begin{array}{l}23.7 \\
(11.5)\end{array}$ & $\begin{array}{l}-12.0 \\
(-16.2 \text { to } \\
-7.9)\end{array}$ & $\begin{array}{l}< \\
0.001\end{array}$ \\
\hline
\end{tabular}

Intervention group received web-based counselling with a cognitive-behavioural approach for eight weeks and control group received no intervention

† Assessed using Daily Record of Severity of Problems (DRSP); the higher score, the sever symptom.

${ }^{\ddagger}$ Assessed using Quality of Life Enjoyment and Satisfaction Questionnaire Short Form (QLES-Q-SF) twice during the period, on day of 1-2 and 11-13 of menstrual period; the higher score, the better quality.

$\int$ Assessed using Sheehan Disability Scale (SDS) at day of 1-2 of menstruation period; the higher score, the sever disability.

** Assessed using Menstrual Attitude Questionnaire (MAQ) at day of 1-2 of menstruation period Values indicate number (percent) or mean (SD) unless otherwise indicated

* Univariate General Linear Models were used to compare post-intervention scores of the groups adjusted for the baseline values using Sidak. Also, Bonferroni correction was used for the multiple comparisons of the primary outcomes. 


\begin{tabular}{|c|c|c|c|c|c|c|}
\hline \multirow[t]{2}{*}{ Outcomes } & \multicolumn{2}{|l|}{ Baseline } & \multicolumn{4}{|c|}{ Post-intervention } \\
\hline & $\begin{array}{l}\text { Intervention } \\
n=46\end{array}$ & $\begin{array}{l}\text { Control } \\
n=46\end{array}$ & $\begin{array}{l}\text { Intervention } \\
\mathrm{n}=42\end{array}$ & $\begin{array}{l}\text { Control } \\
n=46\end{array}$ & $\begin{array}{l}\text { adjusted } \\
\text { difference } \\
(95 \% \mathrm{Cl})\end{array}$ & $\begin{array}{l}\mathrm{p}- \\
\text { value }\end{array}$ \\
\hline $\begin{array}{l}\text { Reduced productivity at } \\
\text { work/school/or home (1- } \\
6 \text { ) }\end{array}$ & $1.7(0.7)$ & $\begin{array}{l}1.8 \\
(0.7)\end{array}$ & $1.3(0.5)$ & $\begin{array}{l}1.9 \\
(0.7)\end{array}$ & $\begin{array}{l}-0.6(-0.8 \\
\text { to }-0.3)\end{array}$ & $\begin{array}{l}< \\
0.001\end{array}$ \\
\hline $\begin{array}{l}\text { Interfered with hobbies or } \\
\text { social activities }(1-6)\end{array}$ & $1.7(0.7)$ & $\begin{array}{l}1.8 \\
(0.8)\end{array}$ & $1.3(0.5)$ & $\begin{array}{l}2.1 \\
(0.7)\end{array}$ & $\begin{array}{l}-0.8(-1.0 \\
\text { to }-0.6)\end{array}$ & $\dot{0.001}$ \\
\hline $\begin{array}{l}\text { Interfered with } \\
\text { relationships with others } \\
(1-6)\end{array}$ & $1.7(0.8)$ & $\begin{array}{l}1.9 \\
(0.9)\end{array}$ & $1.3(0.6)$ & $\begin{array}{l}2.3 \\
(0.7)\end{array}$ & $\begin{array}{l}-0.9(-1.2 \\
\text { to }-0.7)\end{array}$ & $\begin{array}{l}< \\
0.001\end{array}$ \\
\hline \multicolumn{7}{|l|}{ Disability severity $\int$} \\
\hline Total $(0-30)$ & $11.0(6.2)$ & $\begin{array}{l}13.1 \\
(4.6)\end{array}$ & $6.0(4.7)$ & $\begin{array}{l}13.8 \\
(5.0)\end{array}$ & $\begin{array}{l}-6.9(-8.7 \\
\text { to }-5.2)\end{array}$ & $\dot{0} 001$ \\
\hline $\begin{array}{l}\text { In work/school work (0- } \\
\text { 10) }\end{array}$ & $2.9(2.7)$ & $\begin{array}{l}4.1 \\
(2.4)\end{array}$ & $1.6(1.8)$ & $\begin{array}{l}4.1 \\
(2.5)\end{array}$ & $\begin{array}{l}-2.2(-3.1 \\
\text { to }-1.3)\end{array}$ & $\dot{L}_{0.001}$ \\
\hline In social life $(0-10)$ & $4.0(2.6)$ & $\begin{array}{l}4.4 \\
(2.0)\end{array}$ & $2.1(1.8)$ & $\begin{array}{l}4.5 \\
(2.0)\end{array}$ & $\begin{array}{l}-2.4(-3.1 \\
\text { to }-1.7)\end{array}$ & $\dot{0} 001$ \\
\hline $\begin{array}{l}\text { In family life/home } \\
\text { responsibilities }(0-10)\end{array}$ & $4.1(2.6)$ & $\begin{array}{l}4.7 \\
(1.8)\end{array}$ & $2.3(1.9)$ & $\begin{array}{l}5.1 \\
(1.6)\end{array}$ & $\begin{array}{l}-2.7(-3.4 \\
\text { to }-2.0)\end{array}$ & $\dot{0.001}$ \\
\hline \multicolumn{7}{|l|}{ Menstrual Attitude ${ }^{\star *}$} \\
\hline $\begin{array}{l}\text { Menstruation as a } \\
\text { debilitating event (12-84) }\end{array}$ & $59.2(9.2)$ & $\begin{array}{l}58.9 \\
(8.8)\end{array}$ & $52.5(9.9)$ & $\begin{array}{l}56.9 \\
(8.7)\end{array}$ & $\begin{array}{l}-4.7(-7.9 \\
\text { to }-1.6)\end{array}$ & 0.003 \\
\hline
\end{tabular}

Intervention group received web-based counselling with a cognitive-behavioural approach for eight weeks and control group received no intervention

† Assessed using Daily Record of Severity of Problems (DRSP); the higher score, the sever symptom.

‡Assessed using Quality of Life Enjoyment and Satisfaction Questionnaire Short Form (QLES-Q-SF) twice during the period, on day of 1-2 and 11-13 of menstrual period; the higher score, the better quality.

$\int$ Assessed using Sheehan Disability Scale (SDS) at day of 1-2 of menstruation period; the higher score, the sever disability.

** Assessed using Menstrual Attitude Questionnaire (MAQ) at day of 1-2 of menstruation period Values indicate number (percent) or mean (SD) unless otherwise indicated

* Univariate General Linear Models were used to compare post-intervention scores of the groups adjusted for the baseline values using Sidak. Also, Bonferroni correction was used for the multiple comparisons of the primary outcomes. 


\begin{tabular}{|c|c|c|c|c|c|c|}
\hline \multirow[t]{2}{*}{ Outcomes } & \multicolumn{2}{|l|}{ Baseline } & \multicolumn{4}{|c|}{ Post-intervention } \\
\hline & $\begin{array}{l}\text { Intervention } \\
n=46\end{array}$ & $\begin{array}{l}\text { Control } \\
n=46\end{array}$ & $\begin{array}{l}\text { Intervention } \\
\mathrm{n}=\mathbf{4 2}\end{array}$ & $\begin{array}{l}\text { Control } \\
n=46\end{array}$ & $\begin{array}{l}\text { adjusted } \\
\text { difference } \\
(95 \% \mathrm{Cl})\end{array}$ & $\begin{array}{l}\mathrm{p}- \\
\text { value }\end{array}$ \\
\hline $\begin{array}{l}\text { Menstruation as a } \\
\text { bothersome event }(6-42)\end{array}$ & $24.8(6.7)$ & $\begin{array}{l}23.7 \\
(6.1)\end{array}$ & $21.8(6.8)$ & $\begin{array}{l}23.5 \\
(6.6)\end{array}$ & $\begin{array}{l}-2.2(-4.1 \\
\text { to }-0.3)\end{array}$ & 0.022 \\
\hline $\begin{array}{l}\text { Menstruation as a natural } \\
\text { event }(4-28)\end{array}$ & $25.0(5.2)$ & $\begin{array}{l}25.7 \\
(4.5)\end{array}$ & $27.4(4.8)$ & $\begin{array}{l}25.4 \\
(4.7)\end{array}$ & $\begin{array}{l}2.0(0.8 \text { to } \\
3.2)\end{array}$ & 0.002 \\
\hline $\begin{array}{l}\text { Anticipation and prediction } \\
\text { of the onset of } \\
\text { menstruation (4-28) }\end{array}$ & $26.9(3.7)$ & $\begin{array}{l}27.4 \\
(3.6)\end{array}$ & $25.2(5.1)$ & $\begin{array}{l}27.0 \\
(3.5)\end{array}$ & $\begin{array}{l}-1.5(-3.1 \\
\text { to } 0.0)\end{array}$ & 0.059 \\
\hline $\begin{array}{l}\text { Denial of any effect of } \\
\text { menstruation }(7-49)\end{array}$ & $19.8(5.3)$ & $\begin{array}{l}19.0 \\
(4.6)\end{array}$ & $22.3(6.1)$ & $\begin{array}{l}18.5 \\
(5.7)\end{array}$ & $\begin{array}{l}3.3(1.1 \text { to } \\
5.5)\end{array}$ & 0.004 \\
\hline $\begin{array}{l}\text { Intervention group received } \\
\text { weeks and control group rec } \\
\text { † Assessed using Daily Rec } \\
{ }^{\ddagger} \text { Assessed using Quality of } \\
\text { twice during the period, on c } \\
\text { quality. }\end{array}$ & $\begin{array}{l}\text { eb-based coun } \\
\text { ived no interve } \\
\text { d of Severity o } \\
\text { ife Enjoyment } \\
\text { y of } 1-2 \text { and } 11\end{array}$ & $\begin{array}{l}\text { elling with } \\
\text { tion } \\
\text { Problems } \\
\text { nd Satisfa } \\
-13 \text { of mer }\end{array}$ & $\begin{array}{l}\text { a cognitive-be } \\
\text { (DRSP); the hi } \\
\text { ction Question } \\
\text { strual period; } t\end{array}$ & $\begin{array}{l}\text { havioural } \\
\text { her score, } \\
\text { laire Shor } \\
\text { le higher }\end{array}$ & $\begin{array}{l}\text { pproach for } € \\
\text { he sever sym } \\
\text { Form (QLES- } \\
\text { core, the bett }\end{array}$ & $\begin{array}{l}\text { ight } \\
\text { ptom. } \\
\text { Q-SF) } \\
\text { r }\end{array}$ \\
\hline \multicolumn{7}{|c|}{$\begin{array}{l}\int \text { Assessed using Sheehan Disability Scale (SDS) at day of } 1-2 \text { of menstruation period; the higher } \\
\text { score, the sever disability. }\end{array}$} \\
\hline \multicolumn{7}{|c|}{ ** Assessed using Menstrual Attitude Questionnaire (MAQ) at day of 1-2 of menstruation period } \\
\hline \multicolumn{7}{|c|}{ Values indicate number (percent) or mean (SD) unless otherwise indicated } \\
\hline \multicolumn{7}{|c|}{$\begin{array}{l}\text { * Univariate General Linear Models were used to compare post-intervention scores of the groups } \\
\text { adjusted for the baseline values using Sidak. Also, Bonferroni correction was used for the multiple } \\
\text { comparisons of the primary outcomes. }\end{array}$} \\
\hline
\end{tabular}

\section{Primary outcomes}

Following the intervention, the mean score of total PMS symptoms was significantly lower in the intervention group than in the control group (10.4 vs. 20.2 , adjusted difference: $-9.9,95 \% \mathrm{Cl}:-13.3$ to -6.6 , $\mathrm{P}<0.001)$, and the mean score of perimenstrual quality of life was significantly higher (64.2 vs. 50.3, adjusted difference; $14.1,95 \% \mathrm{Cl}: 8.5$ to 19.8$)$. However, the quality of life in the late follicular phase had no significant intergroup difference (68.3 vs. 67.3 , adjusted difference: $1.9,95 \% \mathrm{Cl}$ : -4.4 to 8.1 ).

\section{Secondary outcomes}


Following the intervention, all DRSP sub-scales and severity of PMS-related disability (assessed using the SDS) were significantly different between the groups $(P<0.001$ for all sub-scales except physical symptoms with $P=0.041$ ). In addition, the mean scores of all MAQ domains were significantly higher in the intervention group than in the control group post-intervention $(p<0.05$, except the "anticipation and prediction of the onset of menstruation" with $p=0.059)($ Table 2$)$.

All students of the intervention group were satisfied with the ICBT course and declared that their symptoms had improved post-intervention.

\section{Discussion}

The present study reported that ICBT could significantly reduce the PMS symptom severity and PMSrelated disability, while it improved the quality of life during the premenstrual period (about days - 5 to 2 of the menstrual cycle) and attitude toward menstruation in female university students with PMS. However, it did not significantly affect the quality of life in the late follicular phase (about days 5 to 12 of the menstrual cycle).

Our results of the effectiveness of ICBT on PMS-related factors are compatible with the similar trial in Germany conducted on women with PMDD [31]. In addition, other trials conducted in Iran observed the effectiveness of Internet-based programs on the PMS symptom severity reduction [32,33] and general health improvement [33]. However, the approaches used and intervention durations were not reported in these studies. Also, another trial in Iran [34] showed the positive effect of 10 weekly sessions of cognitivebehavioral group therapy with 90-minute duration. The sessions were not Internet-based and were held by two clinical psychologists for students suffering from PMS in order to improve their health-related quality of life.

One mechanism of the effectiveness of ICBT on PMS patients can be its ability to change their attitudes toward menstruation. A study in Turkey showed that the women suffering from PMS have a significantly higher score in the debilitation subscale and a significantly lower score in the denial subscale of the MAQ than the women without PMS [35]. We also observed the effectiveness of this intervention on improving the scores of the patients in the MAQ subscales, thereby improving their attitudes toward menstruation.

The observed significant effect on quality of life during the perimenstrual period and its ineffectiveness on late follicular quality of life seem logical because the intervention could reduce the severity of premenstrual symptoms, resulting in improving the quality of life during the period. Consistent with the results of another study conducted by the same team [8], in this study, the pretest mean score of quality of life was already significantly higher in the late follicular period than in the perimenstrual period.

It was not possible for the present study to blind the participants, providers, and outcome assessors (the participants were also outcome assessors). However, it seems the risk of different biases was low. The consistent results using several validated, prospective tools for consequence assessment, and no significant effect on the quality of life during the late follicular phase could indicate low detection bias in 
this study. Also, we had a low level of loss to follow-up, which resulted in insufficient plausible effect size to exert a clinically relevant effect on the primary outcomes. Therefore, the risk of attrition bias in the present study was low as well.

Contrary to our previous plans, we could not recruit any participants from the private residence halls because there was no cooperation from the persons in charge. However, the participant allocation was properly randomized and concealed, so there was no selection bias. Also, excluding the students in private residence halls could have little or no effect on the generalizability of the results because just a small percentage $(15 \%)$ of students lived in the private residence halls, and their clinical and demographic characteristics were not significantly different from those living in public residence halls.

We tried to minimize contamination by recruiting only one person from each room in the residence halls, creating a separate account for each participant in the intervention group, and notifying them not to share the content with others until the end of the study.

Given the obtained results, including the intervention effectiveness, high acceptability of the method, low attrition, and high levels of participant satisfaction with the intervention, it seems that the ICBT can be used as a suitable non-pharmacological option to alleviate the PMS symptoms and improve the quality of life of the sufferers. More than $80 \%$ of adults are literate globally [36], with about $50 \%$ of the female population having access to Internet [37]. The data of the 2016 census in Iran showed that $94 \%$ of women of reproductive age were literate, and $55 \%$ had 12 years of education (27\%) or higher (28\%) [38]. Two-thirds (66\%) of Iranian women used the Internet [39], and almost $80 \%$ of households had access to the Internet [40]. Therefore, most women suffering from PMS throughout the world, including Iran, are capable of using the Internet-based therapies.

Internet-based therapies have some benefits over face-to-face counseling sessions. For example, there is no need for the patients to attend a therapy session in a specific location. Thus, the travel expenses and time waste are reduced [41-43]. The educational content is available 24 hours a day [44], and the participants can review the contents several times to minimize the possibility of forgetting the learned topics [45]. It encourages self-care [46] and provides the possibility of confidential communication with the system administrator $[44,47]$.

We did not follow the participants more than two menstrual cycles post-intervention. Thus, it is not possible to comment on the long-term effectiveness of the intervention. In addition, the study participants included only medical students, so results may not be generalized to other populations. Therefore, it is suggested to conduct further studies with longer follow-up durations on other populations such as students in other fields, non-student women, or women of different ages. Also, we recommend investigating the impact of such interventions on the quality of life of the women' family members, such as their husbands, in future studies.

\section{Conclusions}


The present study showed that ICBT could reduce the severity of PMS symptoms and improve the quality of life during the perimenstrual period but have no significant effect on the quality of life in the late follicular phase. In addition, this intervention could improve the attitudes toward menstruation.

\section{Abbreviations}

PMS: Premenstrual Syndrome; ICBT: Internet-Based Cognitive-Behavioral Therapy; DRSP: Daily Record of Severity of Problems; Q-LES-Q-SF: Quality of Life Enjoyment and Satisfaction Questionnaire - Short Form; PMDD: Premenstrual Dysphoric Disorder; PSST: Premenstrual Symptoms Screening Tool; SDS: Sheehan Disability Scale; MAQ: Menstrual Attitude Questionnaire; ICC: intraclass correlation coefficient

\section{Declarations}

\section{Ethics approval and consent to participate}

The Ethics Committee of the Tabriz University of Medical Sciences approved our study protocol with the ethics code IR.TBZMED.REC.1398.014. We followed all the ethical principles of the World Medical Association Declaration of Helsinki for medical research involving human subjects. We obtained written informed consent from all study participants before their recruitment.

\section{Consent for publication}

Not applicable

\section{Availability of data and materials}

The datasets used and/or analysed during the current study are available from the corresponding author on reasonable request.

\section{Competing interests}

The authors declare that they have no competing interests

\section{Funding}

This work was sponsored by the Tabriz University of Medical Sciences (grant number: 62582, 2019). The sponsor had no role in the study design, data collection, analysis, and interpretation, writing of the paper, and the decision for submitting the paper for publication. 


\section{Authors' contributions}

All of the authors contributed to the study's conception, study design, and manuscript revision and approved the final manuscript. In addition, SB had roles in content preparation, intervention implementation, participant recruitment, data collection, data analysis, and draft writing; SM did the project supervision and contributed to the content preparations, data analysis, and writing some parts of the manuscript; KHE contributed to content preparation and administration of the intervention; MM contributed to the content preparations; and AA contributed to the administration of the intervention.

\section{Acknowledgements}

This paper has been extracted from a Master's thesis registered on June 19, 2019, in the Iranian Registry of Clinical Trials with the registry code IRCT20100414003706N34, https://en.irct.ir/trial/38394. We want to acknowledge the residence hall officials for their support as well as the students who agreed to participate in this study.

\section{References}

1. Sigmon ST, Craner J, Yoon KL, Thorpe GL. Premenstrual syndrome (PMS). In: Ramachandran VS, editor. Encyclopedia of human behaviour. 2nd ed. San Diego: Academic Press; 2012. p. 167-73.

2. Sadock BJ, Sadock VA, MD PR. Kaplan and Sadock's synopsis of psychiatry: behavioral sciences/clinical psychiatry. 11th ed. Philadelphia: Walters Kluwer; 2015.

3. American College of Obstetricians and Gynecologists. Premenstrual Syndrome (PMS). https://www.acog.org/Patients/FAQs/Premenstrual-Syndrome-PMS. Updated May 2015.

4. Yonkers KA, O'Brien PS, Eriksson E. Premenstrual syndrome. Lancet. 2008;371:1200-10. https://doi.org/10.1016/S0140-6736(08)60527-9.

5. Potter J, Bouyer J, Trussell J, Moreau C. Premenstrual syndrome prevalence and fluctuation over time: results from a French population-based survey. J Womens Health (Larchmt). 2009;18:31-9. https://doi.org/10.1089/jwh.2008.0932.

6. Siahbazi S, Montazeri A, Taghizadeh Z, Masoomie R. The consequences of premenstrual syndrome on the quality of life from the perspective of affected Women: a qualitative study. J Res Med Dent Sci. 2018;6:284.

7. Dennerstein L, Lehert P, Bäckström TC, Heinemann K. The effect of premenstrual symptoms on activities of daily life. Fertil Steril. 2010;94:1059-64. https://doi.org/10.1016/j.fertnstert.2009.04.023.

8. Quick F, Mohammad-Alizadeh-Charandabi S, Mirghafourvand M. Primary dysmenorrhea with and without premenstrual syndrome: variation in quality of life over menstrual phases. Qual Life Res. 2019;28:99-107. https://doi.org/10.1007/s11136-018-1999-9.

9. Sutcliffe J, Holmes S. Quality of life: verification and use of a self-assessment scale in two patient populations. J Adv Nurs. 1991;16:490-8. https://doi.org/10.1111/j.1365-2648.1991.tb03440.x. 
10. Appleton SM. Premenstrual syndrome: evidence-based evaluation and treatment. Clin Obstet Gynecol. 2018;61:52-61. https://doi.org/10.1097/GRF.0000000000000339.

11. Maddineshat M, Keyvanloo S, Lashkardoost H, Arki M, Tabatabaeichehr M. Effectiveness of group cognitive-behavioral therapy on symptoms of Premenstrual Syndrome (PMS). Iran J Psychiatry. 2016;11:30-6.

12. Kancheva Landolt N, Ivanov K. Short report: cognitive behavioral therapy - a primary mode for premenstrual syndrome management: systematic literature review. Psychol Health Med. 2020; 26:112. https://doi.org/10.1080/13548506.2020.1810718.

13. Shoaee F, Pouredalati M, Dadshahi S, Parvin P, Bolourian M, Kiani A, et al. Evaluation of nonpharmacological strategies, therapeutic and cognitive-behavioral interventions in the treatment of premenstrual syndrome: a review study. Int J Pediatr. 2020;8(2):10929-39. https://doi.org/10.22038/ijp.2020.46333.3771.

14. Başoğul C, Aydın Özkan S, Karaca T. The effects of psychoeducation based on the cognitivebehavioral approach on premenstrual syndrome symptoms: a randomized controlled trial. Perspect Psychiatr Care. 2020;56:515-22. https://doi.org/10.1111/ppc.12460.

15. Mohr DC, Ho J, Duffecy J, Reifler D, Sokol L, Burns MN, et al. Effect of telephone-administered vs face-to-face cognitive behavioral therapy on adherence to therapy and depression outcomes among primary care patients: a randomized trial. JAMA. 2012;307:2278-85.

https://doi.org/10.1001/jama.2012.5588.

16. Kues JN, Janda C, Kleinstauber M, Weise C. Internet-based cognitive behavioural self-help for premenstrual syndrome: study protocol for a randomised controlled trial. Trials. 2014;15:472. https://doi.org/10.1186/1745-6215-15-472.

17. Jacobson JD. Premenstrual syndrome. In: Medical Encyclopedia. MedlinePlus. 1998. https://medlineplus.gov/ency/article/001505.htm. Updated 19 Apr 2018.

18. Mirghafourvand M, Malakouti J, Charandabi SMA, Khalili AF, Homayi SG. The efficacy of lemon balm (Melissa officinalis L.) alone and combined with lemon balm-Nepeta menthoides on premenstrual syndrome and quality of life among students: a randomized controlled trial. J Herb Med. 2016;6:1428. https://doi.org/10.1016/j.hermed.2016.07.001.

19. Hariri FZ, Moghaddam-Banaem L, Siah Bazi S, Saki Malehi A, Montazeri A. The Iranian version of the Premenstrual Symptoms Screening Tool (PSST): a validation study. Arch Womens Ment Health. 2013;16:531-7. https://doi.org/10.1007/s00737-013-0375-6.

20. Steiner M, Macdougall M, Brown E. The Premenstrual Symptoms Screening Tool (PSST) for clinicians. Arch Womens Ment Health. 2003;6:203-9. https://doi.org/10.1007/s00737-003-0018-4.

21. Ghassemzadeh H, Mojtabai R, Karamghadiri N, Ebrahimkhani N. Psychometric properties of a Persian-language version of the Beck Depression Inventory--second edition: BDI-II- Depress Anxiety. 2005;21:185-92. https://doi.org/10.1002/da.20070.

22. Raesian AS, Golzari M, Borjali A. Effectiveness of hope therapy on reducing depressive symptoms and preventing of relapse in cure-seeker women with dependency to narcotic drugs. J Res Addict . 
2011;5:21-40. Persian.

23. Borenstein JE, Dean BB, Yonkers KA, Endicott J. Using the daily record of severity of problems as a screening instrument for premenstrual syndrome. Obstet Gynecol. 2007;109:1068-75. https://doi.org/10.1097/01.AOG.0000259920.73000.3b.

24. Endicott J, Nee J, Harrison W. Daily Record of Severity of Problems (DRSP): reliability and validity. Arch Womens Ment Health. 2006;9:41-9. https://doi.org/10.1007/s00737-005-0103-y.

25. Ozgoli G, Shahveh M, Esmaielli S, Nassiri N. Essential oil of Citrus sinensis for the treatment of premenstrual syndrome; a randomized double-blind placebo-controlled trial. J Reprod Infertil. 2011;12:123-30. Persian.

26. Tagharrobi Z, Sharifi K, Sooky Z, Tagharrobi L. Psychometric evaluation of the Iranian version of Quality of Life Enjoyment and Satisfaction Questionnaire Short Form (Q-LES-QSF). Payesh. 2012;11:235-44. Persian.

27. Sheehan DV, Harnett-Sheehan K, Raj BA. The measurement of disability. Int Clin Psychopharmacol. 1996;11 Suppl 3:89-95. https://doi.org/10.1097/00004850-199606003-00015.

28. Amin-Esmaeili M, Motevalian A, Rahimi-Movaghar A, Hajebi A, Hefazi M, Radgoodarzi R, Sharifi V. The translation and psychometric assessment of the persian version of the sheehan disability scale. Iran J Psychiatry. 2014;9:125-32.

29. Rush AJ, First MB, Blacker D. Handbook of psychiatric measures. 2nd ed. Washington (DC): American Psychiatric Publication; 2008.

30. Brooks-Gunn J, Ruble DN. The menstrual attitude questionnaire. Psychosom Med. 1980 Sep;42:50312. https://doi.org/ 10.1097/00006842-198009000-00005.

31. Weise C, Kaiser G, Janda C, Kues J, Andersson G, Strahler J, et al. Internet-based cognitivebehavioural intervention for women with premenstrual dysphoric disorder: a randomized controlled trial. Psychother Psychosom. 2019;88:16-29. https://doi.org/10.1159/000496237.

32. Karami J, Zabet M, Rahmani S, Zalipour S. The effect of webotherapy on premenstrual syndrome. Nurs Midwifery J. 2016;13:1016-21. Persian.

33. Bastani F, Hashemi S. Effects of a web based lifestyle education on general health and severity of the symptoms of Premenstrual Syndrome (PMS) among female students: a randomized controlled trial. Procedia Soc Behav Sci. 2012;46:3356-62. https://doi.org/10.1016/j.sbspro.2012.06.066.

34. Izadi-Mazidi M, Davoudi I, Mehrabizadeh M. Effect of group cognitive-behavioral therapy on healthrelated quality of life in females with premenstrual syndrome. Iran J Psychiatry Behav Sci. 2016;10:e4961. https://doi.org/10.17795/ijpbs-4961.

35. Guvenc G, Kilic A, Akyuz A, Ustunsoz A. Premenstrual syndrome and attitudes toward menstruation in a sample of nursing students. J Psychosom Obstet Gynaecol. 2012;33:106-11. https://doi.org/10.3109/0167482X.2012.685906.

36. O'Neill A. Global literacy rate 1976-2016. 2019. https://www.statista.com/statistics/997360/globaladult-and-youth-literacy/. Cited 3 Mar 2021. 
37. Johnson J. Global internet usage rate by gender and market 2019. 2021.

https://www.statista.com/statistics/333871/gender-distribution-of-internet-users-worldwide/. Cited 3 Mar 2021.

38. Statistical Center of Iran: 2\% Raw data of the national population and housing census 2016 [individual file].

https://www.amar.org.ir/\%D8\%B3\%D8\%B1\%D8\%B4\%D9\%85\%D8\%A7\%D8\%B1\%DB\%8C\%D8\%B9\%D9\%85\%D9\%88\%D9\%85\%DB\%8C-\%D9\%86\%D9\%81\%D9\%88\%D8\%B3-\%D9\%88\%D9\%85\%D8\%B3\%DA\%A9\%D9\%86/\%D9\%86\%D8\%AA\%D8\%A7\%DB\%8C\%D8\%AC\%D8\%B3\%D8\%B1\%D8\%B4\%D9\%85\%D8\%A7\%D8\%B1\%DB\%8C. Cited 3 Mar 2021.

39. International Telecommunication Union. Gender ICT statistics. https://www.itu.int/en/ITUD/Statistics/Pages/stat/default.aspx. Cited 3 Mar 2021.

40. International Telecommunication Union. Core indicators on access to and use of ICT by households and individuals. https://www.itu.int/en/ITU-D/Statistics/Pages/stat/default.aspx. Cited 3 Mar 2021.

41. Otten E, Birnie E, Ranchor AV, van Langen IM. Online genetic counseling from the providers' perspective: counselors' evaluations and a time and cost analysis. Eur J Hum Genet. 2016;24:125561. https://doi.org/10.1038/ejhg.2015.283.

42. Wootton R, Tait A, Croft A. Environmental aspects of health care in the Grampian NHS region and the place of telehealth. J Telemed Telecare. 2010;16:215-20. https://doi.org/10.1258/jtt.2010.004015.

43. Russo JE, McCool RR, Davies L. VA telemedicine: an analysis of cost and time savings. Telemed J E Health. 2016;22:209-15. https://doi.org/10.1089/tmj.2015.0055.

44. Harris B, Birnbaum R. Ethical and Legal Implications on the Use of Technology in Counselling. Clin Soc Work J. 2014;43:133-41. https://doi.org/10.1007/s10615-014-0515-0.

45. Tirel M, Rozgonjuk D, Purre M, Elhai J. When do people seek internet counseling? exploring the temporal patterns of initial submissions to online counseling services. J Tech Hum Serv. 2020;38:184-202. https://doi.org/10.1080/15228835.2018.1561348.

46. Barbosa EM, Sousa AA, Vasconcelos MG, Carvalho RE, Oriá MO, Rodrigues DP. Educational technologies to encourage (self) care in postpartum women. Rev Bras Enferm. 2016;69:582-90. English, Portuguese. https://doi.org/10.1590/0034-7167.2016690323i.

47. Young KS. An empirical examination of client attitudes towards online counseling. Cyberpsychol Behav. 2005;8:172-7. https://doi.org/10.1089/cpb.2005.8.172.

\section{Figures}




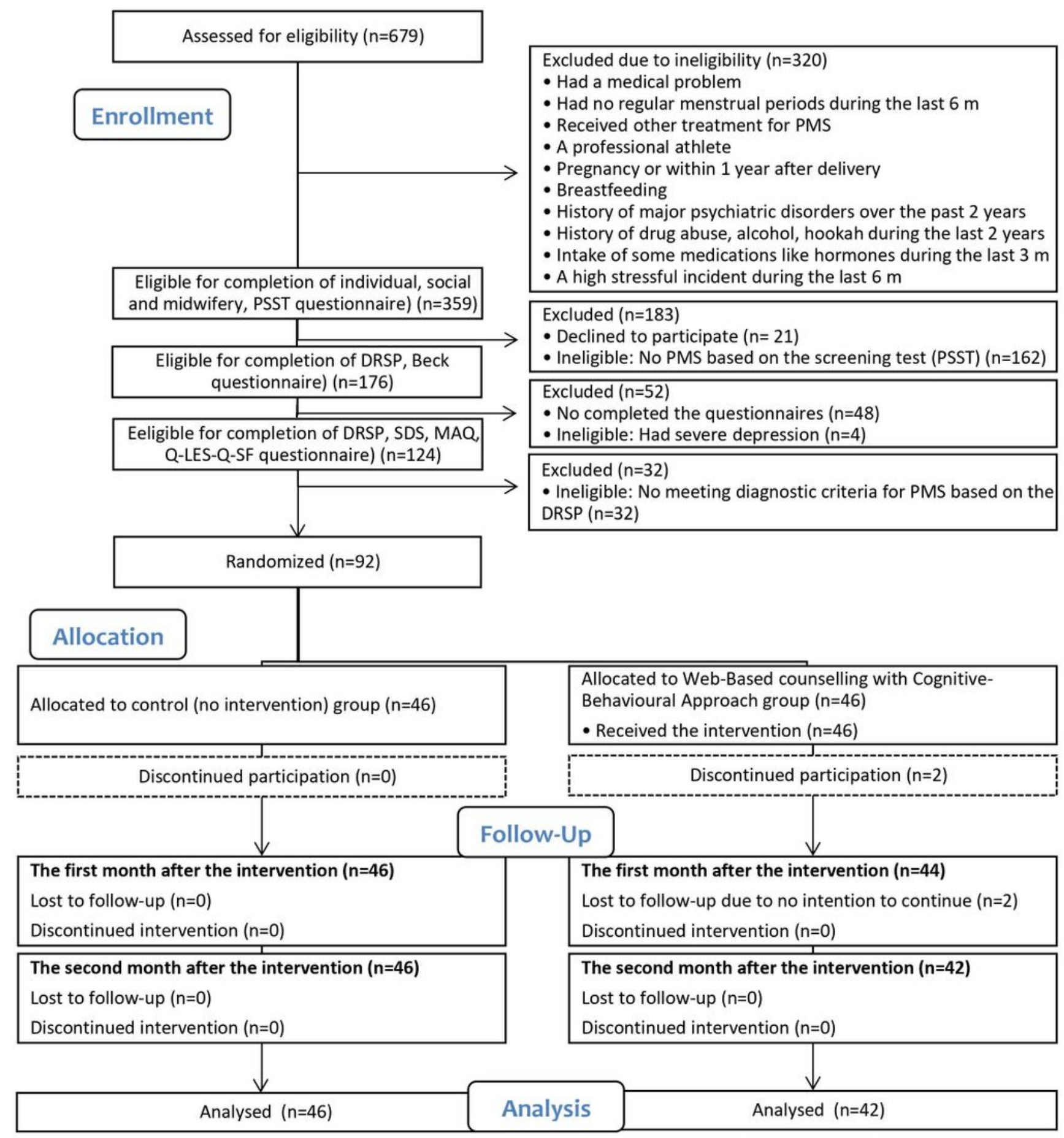

PMS: premenstrual syndrome, PSST: Premenstrual Symptoms Screening Tool, DRSP: Daily Record of Severity of Problems, SDS: Sheehan Disability Scale, MAQ: Menstrual Attitude Questionnaire, QLES-Q-SF: Quality of Life Enjoyment and Satisfaction Questionnaire Form

\section{Figure 1}

Flow diagram

\section{Supplementary Files}

This is a list of supplementary files associated with this preprint. Click to download. 
- CONSORT2010ChecklistBorji.doc 